\title{
Squaring the Circle: A Mathematically Rigorous Physics First
}

Robert Goodman, Bergen County Technical High School, Teterboro, NJ

Eugenia Etkina, Graduate School of Education, Rutgers University, New Brunswick, NJ

F or more than a hundred years there has been a debate about the sequence in which high school science should be taught. Many advocates of "Physics First" support a more conceptual ninth-grade physics course followed by chemistry and then biology while supporters of mathematically rigorous physics favor a sequence of biology-chemistry-physics. This paper describes a new approach that incorporates some of the best arguments from both sides. The main idea is to teach a mathematically rigorous ninth-grade physics course based on algebra alone, avoiding trigonometry. ${ }^{1,2} \mathrm{By}$ selecting topics from the AP Physics B curriculum that form a foundation for both chemistry and biology, one can establish an efficient science sequence. The goal of this paper is to describe this new approach to Physics First and present data supporting its effectiveness.

\section{A Problem: Logical Flow or Mathematical Physics?}

The sequence in which the sciences are taught has been an area of contention for more than 100 years, since the Committee of Ten established the current sequence in $1892 .{ }^{3}$ Should the sequence of science be physics-chemistry-biology or biologychemistry-physics? This conflict arose because the former sequence supports the logical flow of the sciences while the latter aligns physics and its requisite mathematics.

The sequence of physics-chemistry-biology is logical, ${ }^{4-10}$ as biology requires a foundation of both chem- istry and physics, and chemistry requires a foundation of physics. The reverse is not the case.

The sequence biology-chemistry-physics has been considered to better align physics and mathematics, as most students do not learn basic trigonometry until 10 th grade, and trigonometry has been considered necessary for high school physics. This required physics to be the 11 th-grade science, leading to the traditional biology-chemistry-physics sequence.

As biology has become increasingly analytical, the importance of flow became stronger and led to an increasing number of "Physics First" experiments. ${ }^{11,12}$ However, the lack of trigonometry knowledge amongst ninth-grade students gave impetus to a conceptual, almost "nonmathematical" approach in Physics First courses. 5,6 This approach diminished the value of Physics First to those who consider physics to be a mathematical science. ${ }^{4,7,8,10-12}$

\section{Solution: Algebra-Based Ninth-Grade Physics}

The conflict between logical flow and the lack of trigonometry knowledge among ninth-grade students can be resolved by teaching a ninth-grade mathematically intensive physics course based on algebra alone, without trigonometry. ${ }^{1}$ This approach represents a major departure from "conceptual physics" but is within the grasp of anyone with a basic understanding of algebra. A careful analysis of physics curricula shows that only about $10-15 \%$ of the content requires trigonometry. Students can comprehend the rest of the material and solve challenging problems 
only using algebra. The argument that ninth-graders are weak in algebra or are taking it in parallel with physics only strengthens the argument for algebrabased physics. Students can master algebra while they are learning physics, using physics as a context. Of course this approach will lead to some omissions in content. This can be addressed by offering students who choose to take it a second year of physics, AP B Physics, which is closely linked to the first-year course.

In the ninth-grade course the first semester is devoted to mechanics and the second to electricity and magnetism, both of which are essential to chemistry and biology. Concepts such as energy, force, electric charges, electric field, and atomic structure are all prerequisite for understanding chemistry and then biology; the ninth-grade physics course lays that foundation.

Students can then move on to the second-year physics course-AP Physics B. In this course they spend some time solving those problems in mechanics and electricity that require trigonometry, extending these two topics, and most of their time on additional topics. The ninth-grade course can stress depth of understanding rather than covering many topics since all students who are interested enough to study further can take the AP B course. Developing problem-solving skills and conceptual understanding are two interconnected goals of the course.

While a key advantage of this approach is to build mathematical skills in the context of a physics course, this does not require strong coordination between mathematics and science teachers, nor would that coordination be generally possible. This is because students will be in different math classes while taking this course (i.e., while most are in Algebra I, some are in Geometry and Algebra I, some are in Geometry alone, and others are in Math Analysis I).

\section{Pedagogical Approach}

All students in the school, with a wide range of prior experience and success in mathematics and science, take a mathematically rigorous physics course in ninth grade. Being successful with such a diverse population required developing appropriate pedagogical techniques and curricular materials. Due to space limitations, a thorough discussion of these has been reserved for an online appendix. ${ }^{13}$ However, space does permit a general description.
We use a social constructivist approach that strongly encourages students to work together to build understanding. While conceptual understanding is a core principal, so is problem solving. Students construct their understanding when they are challenged to apply new concepts to increasingly complex, interesting problems; much of the time in class is devoted to this.

Formative assessment is ongoing and essential to the entire learning and teaching process. In fact, the only student assessments that are not formative in nature are the midterm, final exam, and the AP exam. Students may, and are encouraged to, retake new versions of all other assessments; only their highest scores count.

All major tests use the AP format (half multiple choice and half free response) and scoring approach. Tests are curved using a modified version of the curve used for the AP exam itself (where a score of about $65 \%$ equates to a 5 , their "A"). We only include grades on test and laboratory work in the student's course grade: homework, participation, etc. play no direct role. The result has been a very strong correlation between course grades and AP scores.

All students in the school take the same tests on the same day. This extends the social constructivist approach beyond the classroom to the entire school. All students can work together to prepare for tests or retests and to complete laboratory work. This has facilitated another key element in the program, establishing after-school sessions twice a week where students, in the same or different grades, and teachers work together in a collaborative, constructivist fashion.

\section{Second Year Physics: The Completion of AP Physics B}

All students in the school complete about half of the AP Physics B curriculum by the end of ninth grade. They are well positioned to complete AP Physics, if they choose to take the second-year course, and then take the exam (a requirement for all AP courses in the school) in 10th grade or in a later year. They simply add the extra level of mathematical sophistication required for trigonometry-based problems to their ninth-grade study of mechanics and E\&M and the additional topics from the AP B curriculum.

This new way of dividing that AP B curriculum 


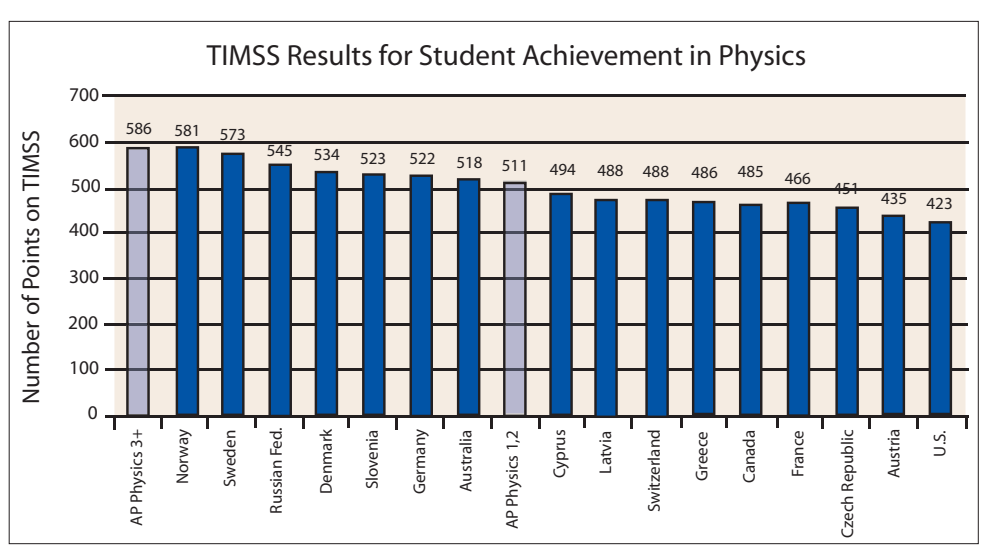

Fig. 1. TIMSS Report: International Student Achievement in Physics.

over two years, to match against the growing mathematical skills of the students, is fundamental to this new approach. A good example is how we approach the topic of projectile motion.

Traditionally, vectors appear early in a physics course, immediately subsequent to the development of kinematics. They can be oriented at any angle, requiring knowledge of trigonometry. However, in our ninth-grade course students learn kinematics with vectors that are only parallel, anti-parallel, or perpendicular to one another; there's no need for trigonometry. The saved time is devoted to "one-dimensional" dynamics. Students solve problems involving forces exerted parallel, anti-parallel, and in some cases perpendicular to one another without the use of trigonometry.

The next year, in the AP Physics B course, the concepts of trigonometry simply add extra steps to the beginning and end of these dynamics and kinematics problems. For example, in projectile-motion problems, students first resolve the vector into its horizontal and vertical components using trigonometry. They then use what they learned in ninth grade to solve the two resultant one-dimensional problems in the horizontal and vertical dimensions. Finally, they compose the solution vector from its components, once again using trigonometry. None of the work done the prior year was wasted.

\section{Chemistry and Biology}

In a similar manner, the 10 th-grade chemistry course is composed of about half the content from the AP Chemistry curriculum, and the 11th-grade biology course draws its content from the AP Biology curriculum. By choosing the proper set of topics, we created three science courses, in physics, biology, and chemistry, that each serves as either the first half of an AP course or as a strong stand-alone course. We also take advantage of the overlap between the AP topics in physics, chemistry, and biology to eliminate redundancy and increase curriculum efficiency.

\section{Is AP Emphasis Productive?}

One might wonder if the emphasis on the AP physics, chemistry, or biology is a productive way to improve science education. A strong support for our argument comes from the study of Gonzalez, O'Connor and Miles, ${ }^{14}$ who reported that although overall the United States performed at the bottom of the list of 16 countries in the 1998 TIMSS (Trends in Mathematics and Science Study) Physics test, students who took the AP Physics exam and scored less than a 3 were in the middle of the list. American students who passed the AP exam, by earning a score of 3 or higher, were at the top of the list. They outperformed every other country. ${ }^{15}$ Figure 1 shows that American students who have an opportunity to take an AP physics course compete successfully with the best students in the world.

\section{Student Achievement in Physics}

The new science sequence was implemented in a county vocational/technical high school that was founded in New Jersey in 1999. The population of the school is not unusually strong in terms of mathematical aptitude. Over the last three years the students' mathematical and verbal SAT scores were within $1 / 10$ of a standard deviation of the state average. Since the same school district has magnet schools for both science and mathematics as well as for engineering, students who have been identified as exceptional in these areas do not attend the school under study. On the other hand, students need to apply and be accepted to the vocational/technical school in order to attend, so very weak students are also not present on the campus.

\section{AP Results as a Measure of Student Achievement}

We chose as one of the measures of the effectiveness 
of the new science program the number of students taking and passing, scoring 3 or higher, AP physics exams. As discussed above, student performance on AP exams gives an indication of their achievement against an international standard. ${ }^{14}$

We report the number of exams taken and the number of passing scores achieved in two ways: by total number as well as by a normalized comparison to New Jersey (to control for school size). Normalized data are calculated by dividing the percentage of graduating seniors in the school who achieved a result by the percentage of graduating seniors in the state who achieved that same result. A normalized result of " 1 " would indicate that the school is performing at the same level as the overall state, a result of 2 would mean that the school is performing at twice that rate, etc.

\section{Participation and Passing Rates on AP Physics Exams}

The program started with ninth-graders in 1999/2000, and the first AP results were for 2003. Figure 2 shows the total number of AP Physics exams taken by year while Fig. 3 reports the normalized result. For instance, Fig. 3 indicates that in 2006, students at the school took AP Physics B exams at a rate that was 14 times that of the overall state.

Although simply taking an AP test has a positive impact on student learning, it is certainly better to pass the test. Those who passed the AP Physics B test scored 75 points higher on the TIMSS (586 versus 511) than those who did not; those who took the AP Physics B test and did not pass still scored 88 points higher (511 versus 423 ) than the overall U.S. result.

Figure 4 and Fig. 5 give the total and normalized numbers of passed AP physics exams for the school. Even though 14 times as many students at the school are taking the Physics AP B exam, this has not lowered the passing rate, which is more than 14 times that of the state.

\section{Science Results Beyond Physics}

The goal of this science program was to improve student achievement in overall science and mathematics, not just in physics. Space permits only a brief report of the results for the other sciences; a more detailed report appears in a separate article. ${ }^{2}$

Overall interest in science has risen steadily. In

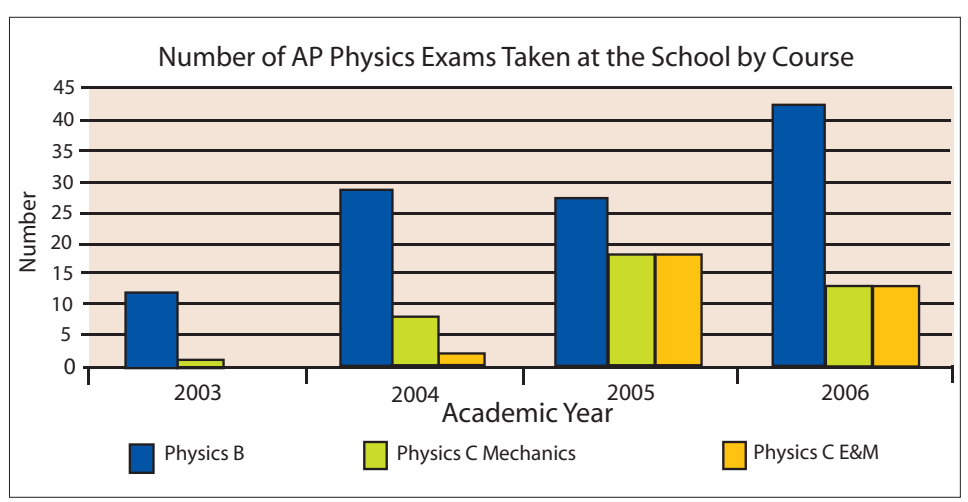

Fig. 2. Number of AP Physics exams taken at the school by course.

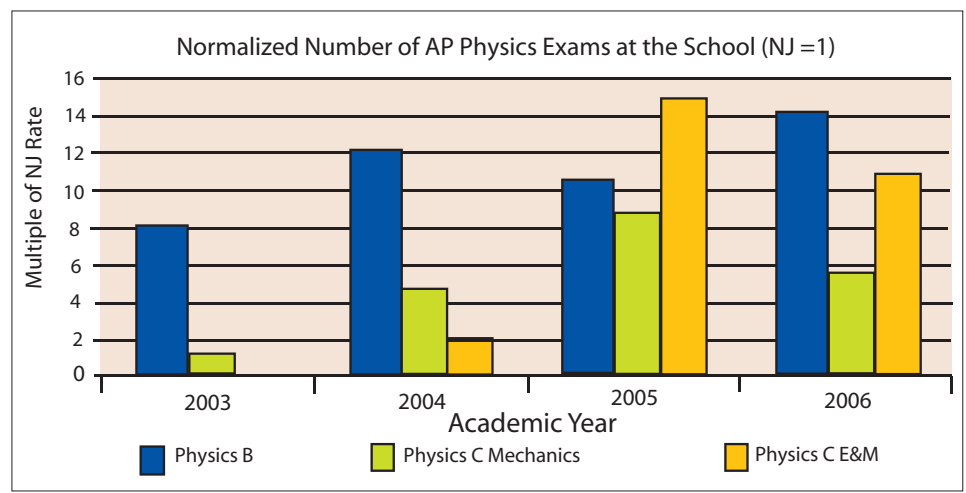

Fig. 3. Normalized number of AP Physics exams taken at the school by course.

2003, students took an average of 3.4 years of science, 0.4 years beyond the three required years; by 2006 that had risen to 4.2 years; students were electing to take an average of 1.2 years of science beyond the minimum. While much of this was due to the growing participation in AP science courses, there was also a marked increase in the enrollment of non-AP science courses. For instance, Anatomy and Physiology was the third most popular course, taken by about $23 \%$ of the students, and Earth Science was ranked fifth with an enrollment of about $12 \%$ of the students.

By 2006, students in the school were taking and passing AP science courses at a rate that was about 4.5 times that of the state. While a large part of that was in physics, Fig. 6 shows that the other AP sciences exceed the state rate by factors of between two and six. Passing rates on these exams are similarly impressive.

\section{Summary}

In this paper, we described a program that provides 


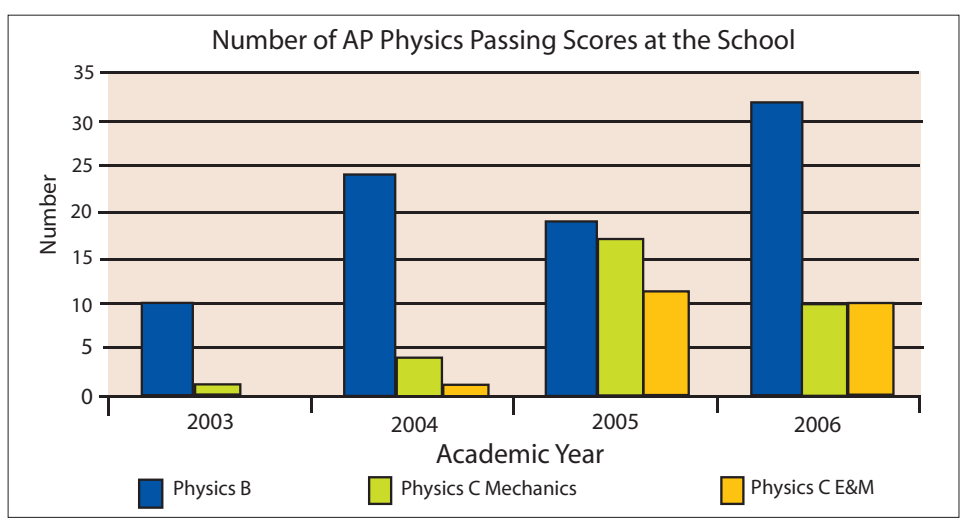

Fig. 4. Number of passing scores by course.

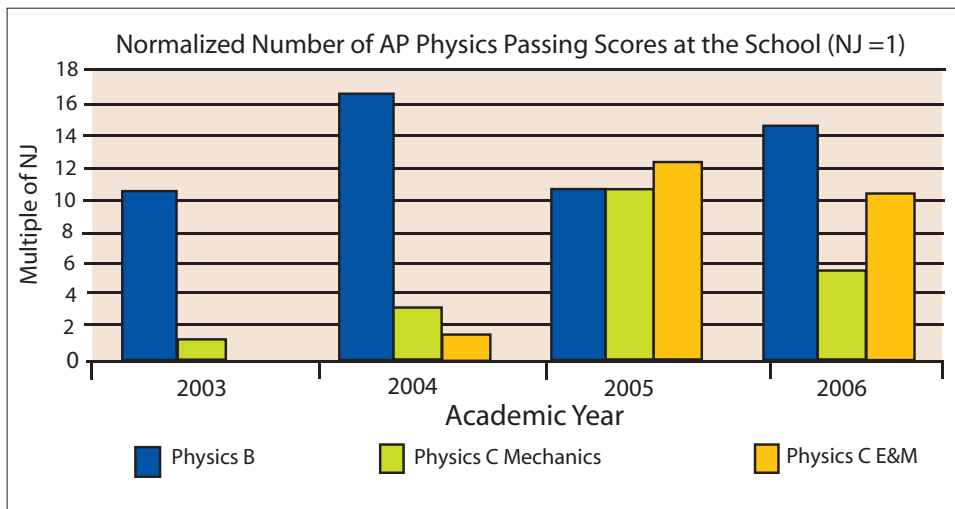

Fig. 5. Passing scores on AP Physics exams normalized to New Jersey results.

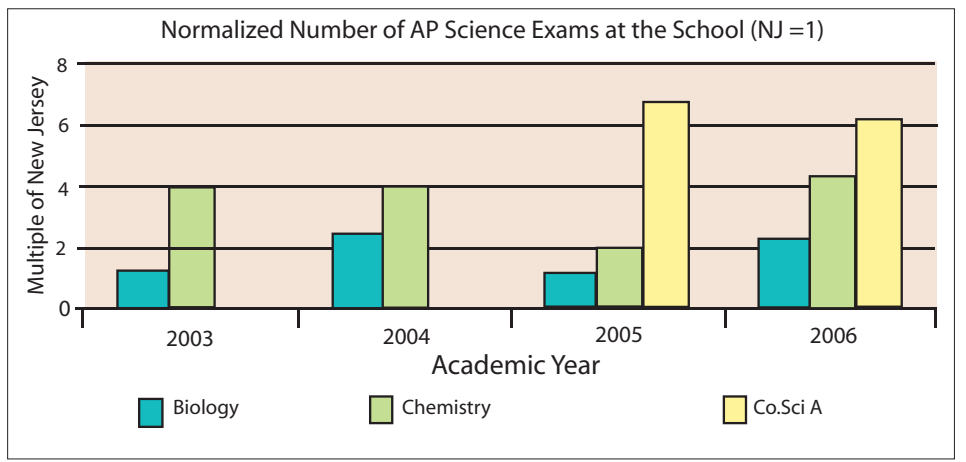

Fig. 6. Normalized number of other AP Science exams by course (NJ = 1).

a new alternative in the debate between "Physics First" and the traditional science sequence. A key element of the new program is a mathematically rigorous ninthgrade algebra-based physics course. By drawing the topics for that ninth-grade physics course from the Physics AP B curriculum, we showed that it is possible to teach all students the first half of AP Physics $\mathrm{B}$ and then give them the choice of going on to com- plete that curriculum in 10th grade, in parallel with studying chemistry, or thereafter. Thus a very large number of students can stay "in the game" of learning advanced science for a longer period of time. For instance, an unusually large percentage of the students in the school take AP Physics B prior to graduation, averaging about $20 \%$ (as a percentage of graduating seniors) in 2004 and 2005 and reaching nearly $30 \%$ in 2006. The AP Physics B topics taught in that ninth-grade course are also specifically chosen to create a foundation for chemistry and biology.

Repeating this process by making chemistry the first half of a two-year AP Chemistry sequence and biology the first half of a two-year AP Biology sequence gives all students a serious introduction to those subjects so they can continue on to take the AP course and exam later.

Two of the key effects of this new program were to radically increase the rate at which students at the school both take and pass AP Physics B exams to 14 times the rate for New Jersey. This means that a much higher percentage of the students at the school were reaching levels of achievement that met or exceeded international standards.

\section{References}

1. R. Goodman, "A New High School Program and Its Effect on Student Achievement in Mathematics and Science," in Science Education (Rutgers University Graduate School of Education, New Brunswick, NJ, 2006).

2. R. Goodman and E. Etkina, "Mathematical Rigor + Physics First = Improved Science Achievement." Submitted to School Science and Mathematics, 2007.

3. K. Sheppard, "Physics First," Principal Leadership 3 67-70 (Sept. 2002).

4. U. Haber-Schaim, "High school physics should be taught before chemistry and biology," Phys. Teach. 22, 330-332 (May 1984).

5. L.M. Lederman, "A new high school science curriculum," Phys. Today 48, 11-13 (April 1995).

6. L.M. Lederman, "Getting high school science in order," Tech. Rev. 99, 61-63 (April 1996).

7. L.M. Lederman, "Revolution in science education: Put physics first!” Phys. Today 54, 11-12 (Sept. 2001).

8. L.M. Lederman, "The Role of Physics in Education," in Biology and the Physics First Curriculum: A Symposium Celebrating BSCS's 45th Anniversary (BSCS, Colorado Spring, CO, 2003). 
9. L.M. Lederman, "Physics first?" Phys. Teach. 43, 6-7 (Jan. 2005).

10. M.G. Bardeen and L.M. Lederman, "Science education: Coherence in science education," Sci. 281, 178179 (1998).

11. G. Ewald et al., "Physics first: The right-side-up science sequence," Phys. Teach. 43, 319-320 (May 2005).

12. P. Hickman, "Freshman physics?" Sci. Teach. 57, 45-47 (1990).

13. View the online appendix at http://ftp.aip.org/cgi-bin/ epaps?ID=E-PHTEAH-46-xxxx). For more information on EPAPS, see http://www.aip.org/pubservs/epaps.

14. E.J.Gonzalez, K.M. O'Connor, and J.A. Miles, How Well Do Advanced Placement Students Perform on the TIMSS Advanced Mathematics and Physics Tests? (The International Study Center, Boston College, 2001).

15. The College Board, Frequently Asked Questions About the AP Program. 2006; Available from: http://www. collegeboard.com/prod_downloads/prof/

advance-placement-qa.pdf. The chart appears on page 4 of this pdf.

PACS codes: KARL

Bob Goodman is the science chair and a physics teacher at his school as well as the 2006 New Jersey State Teacher of the Year. He received his BS in physics from MIT; his MAT in teaching physics from SUNY Stony Brook and his EdD in science education from Rutgers University, where Eugenia Etkina was his doctoral advisor.

Bergen County Technical High School, 504 Route 46 West, Teterboro, NJ 07608; bgoodman33@gmail.com

Eugenia Etkina is an associate professor of science education at Rutgers University. She works with pre- and in-service physics teachers and with colleagues in physics who are reforming undergraduate physics courses. She co-directs Rutgers Astrophysics Institute.

Graduate School of Education, Rutgers University, 10 Seminary Place, New Brunswick, NJ 08901; etkina@rci.rutgers.edu

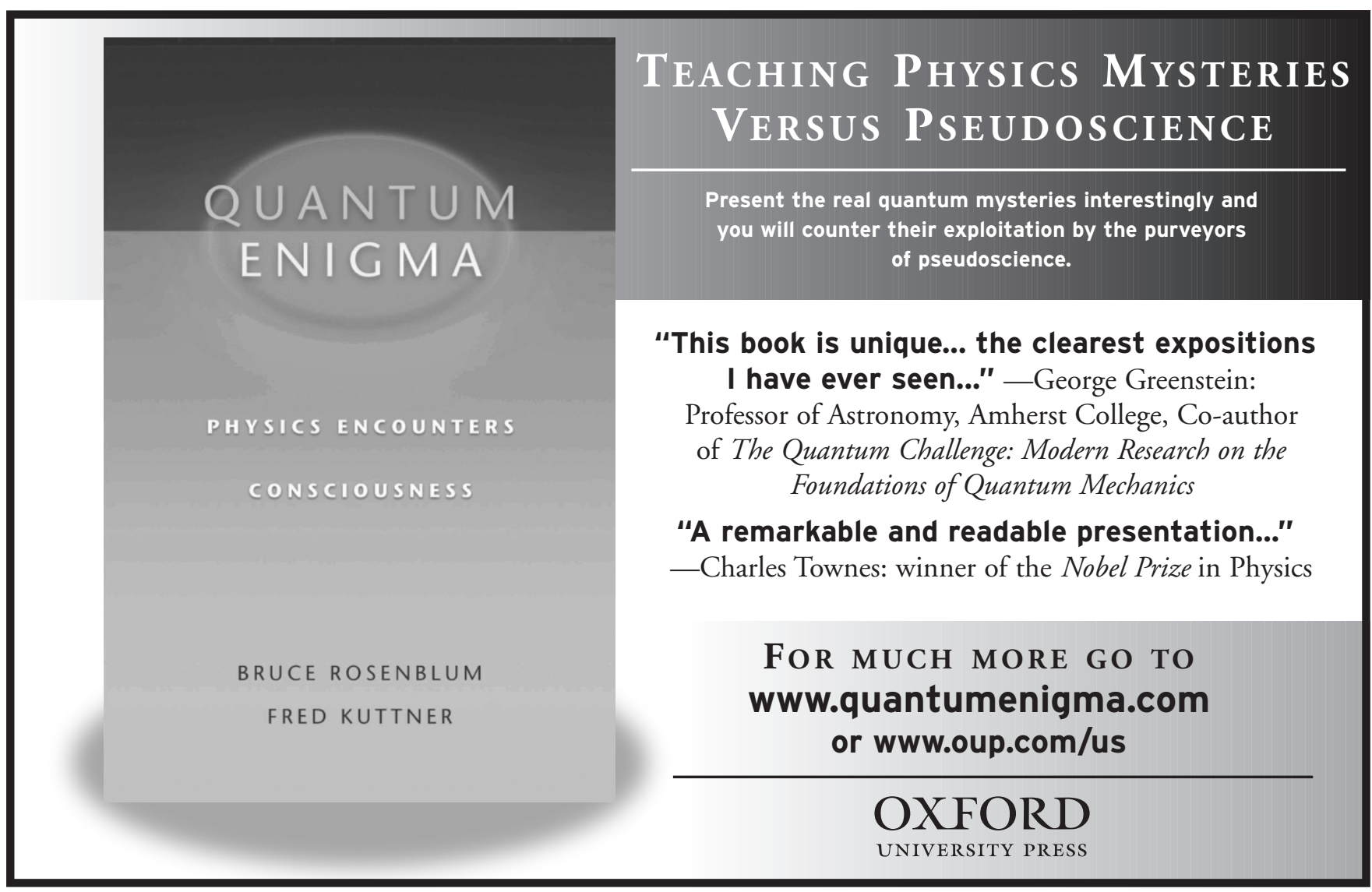

